\title{
Análise econômica de quatro estratégias de suplementação para recria e engorda de bovinos em sistema pasto-suplemento
}

\section{Darcilene Maria de Figueiredo ${ }^{1}$, André Soares de Oliveira ${ }^{1}$, Maykel Franklim Lima Sales ${ }^{1}$ Mário Fonseca Paulino ${ }^{2}$, Sônia Maria Leite Ribeiro do Vale ${ }^{3}$}

1 Doutorando DZO/UFV, Viçosa, MG, CEP: 36571-000

2 DZO/UFV, Viçosa, MG, CEP: 36571-000.

${ }^{3}$ DER/UFV, Viçosa, MG, CEP: 36571-000.

\begin{abstract}
RESUMO - Objetivou-se com este estudo avaliar as respostas produtiva e econômica de quatro estratégias de suplementação durante o ciclo produtivo de bovinos de corte recriados e terminados em pastagens tropicais. Os dados sobre consumo de suplemento e desempenho dos animais foram obtidos de seis experimentos utilizando 196 animais em pastejo. As estratégias de suplementação avaliadas basearam-se na idade ao abate dos animais (18, 24, 30 e 40 meses), idealizando-se um sistema de produção com área de 1.000 ha e taxa de lotação média de $1 \mathrm{UA} / \mathrm{ha} /$ ano. O ganho de peso médio anual dos animais abatidos aos $18,24,30$ e 40 meses de idade foi de 0,$76 ; 0,48 ; 0,35$ e $0,23 \mathrm{~kg} /$ animal/dia, respectivamente, e proporcionou os seguintes números de ciclos de produção $(1,20 ; 0,75 ; 0,55$ e 0,38 ciclos/ano). O abate aos 40 meses foi a única estratégia de suplementação que apresentou margem bruta negativa, indicando insustentabilidade a curto prazo neste sistema. A margem líquida anual foi positiva para as idades de abate de 18 ( R $\$ 220.766,39)$ e 30 meses ( $\$$ 80.395,24) e negativa para 24 meses de idade. O alto consumo de suplemento e a concentração deste conumo em uma fase de pior conversão alimentar foram as causas da pior resposta econômica obtida com o abate aos 24 meses em relação ao abate aos 18 e aos 30 meses. As taxas de retorno do capital investido com terra (TRC), 5,48 (18 meses), -1,60 (24 meses), 1,16 (30 meses) e -1,67\% ao ano (40 meses) indicaram que apenas o abate aos 18 meses permite a sobrevivênvia do empreendimento a longo prazo. A maior resposta produtiva a essa estratégia, em razão do menor nível diário de suplementação e do fornecimento de concentrado em fase de maior eficiência alimentar, explica os melhores resultados econômicos. Todavia, a escolha da melhor estratégia de suplementação depende de combinações favoráveis de preços relativos dos suplementos e pode ser definida pela diferença na TRC em relação à ausência de suplementação, estimada para cada estratégia.
\end{abstract}

Palavras-chave: pecuária de corte, plano nutricional, rentabilidade, sistema de produção

\section{Economic analysis of four supplementation strategies for growth and finish beef cattle in a pasture-supplement system}

\begin{abstract}
The productive and economic response of four feeding systems during the productive cycle of beef cattle raised and finished in tropical pastures was evaluated in this research. The data on supplement intake and performance of the animals were obtained from six experiments using 196 grazing animals. The evaluated supplementation strategies was based on the slaughter age of the animals $(18,24,30$, and 40 months), simulating a ideal system of production with area of 1.000 ha and annual average carrying capacity of 1 AU/ha/year. The annual average weight of the slaughtered animals at 18, 24, 30 and 40 months of age was of $0.76,0.48,0.35$, and $0.23 \mathrm{~kg} /$ animal/day, respectively, and provided the following of cycles of production numbers $(120,0.75,0.55$, and 0.38 cycles/year). The 40 mo slaughter age was the only supplementation strategy that showed negative gross margin, indicating short-term in sustainability in this system. The annual net margin was positive for the slaughter ages 18 (R\$ 220,766, 39) and 30 months (R\$ 80,395. 24) and negative for 24 months of slaughter age. The high intake of supplement and the concentration of this intake in a phase of worse feed conversion was the causes of the worse economic response obtained with the slaughter age of 24 months in relation to slaughter age of 18 and the 30 mo. The return taxes of the invested capital with land (TRC), 5.48 (18 mo), -1.60 (24 mo), 1.16 (30 mo) and -1.67\% a year (40 mo) indicated that only the slaughter age of 18 mo allows the carry on of the enterprise in a long run. The biggest productive response to this strategy, in reason of the lesser daily level of supplementation and of the supply concentrated of in a phase of bigger feed efficiency, explains the best economic results. However, the choice of the best supplementation strategy depends on favorable combinations of relative prices of the supplements and could be defined by the difference in the TRC in relation to the absence of supplementation, estimate for each strategy.
\end{abstract}

Key Words: beef cattle, nutritional plan, production systems, profitability 


\section{Introdução}

Com clima favorável e abundância territorial e de vegetação, o Brasil é líder em produção de carne no mundo. Porém, a pecuária brasileira enfrenta a sazonalidade de produção das plantas forrageiras e deficiências nutricionais da pastagem, base do sistema de criação. De modo geral, há excesso de produção no período das águas e escassez na seca. Assim, a aplicação de tecnologias que otimizem o desempenho animal é fundamental para a conquista do mercado de forma sustentável e competitiva.

Existem duas formas básicas de interferir no ganho financeiro real de uma atividade: aumentando seu preço de venda, mas com algumas conseqüências em relação à demanda, ou implementando uma política de redução de custos e aumento de produtividade, que também favoreceria o aumento da margem sem, contudo, depender diretamente do fator demanda.

Enquanto a viabilidade técnica da suplementação de animais em pastejo é considerada praticamente consolidado, questionamentos quanto a sua viabilidade econômica existem desde longa data, muito embora comparações econômicas entre os sistemas intensivos e extensivos de pecuária tenham apontado para resultados superiores para os sistemas intensivos (Pilau et al., 2003).

Segundo Paulino et al. (2004), a suplementação de bovinos em pastejo é uma das principais estratégias para a intensificação dos sistemas primários regionais. Esta tecnologia permite corrigir dietas desequilibradas, aumentar a eficiência de conversão das pastagens, melhorar o ganho de peso dos animais, encurtar os ciclos reprodutivos, de crescimento e engorda dos bovinos e aumentar a capacidade de suporte dos sistemas produtivos, incrementando a eficiência de utilização das pastagens em seu pico de produção e elevando o nível de produção por unidade de superfície ( $\mathrm{kg} / \mathrm{ha} / \mathrm{ano})$. Para isso, é necessária, além da intenção, uma atitude empresarial por parte dos pecuaristas, entendendo e tomando decisões a partir de análises de formação de custos e rentabilidade do setor. Deve-se estabelecer um plano anual a ser aplicado dentro das possibilidades da empresa rural para se chegar a uma condição de alta lucratividade (Nogueira, 2003).

Neste estudo, objetivou-se avaliar as respostas produtiva e econômica de quatro sistemas de alimentação durante o ciclo produtivo de bovinos de corte recriados e terminados em pastagens tropicais como alternativa de redução da idade ao abate.

\section{Material e Métodos}

Para realizar as análises econômico-financeiras, foram analisados o perfil tecnológico, os indicadores de tamanho, os indicadores zootécnicos e os indicadores econômicos de diferentes sistemas de produção utilizando-se planilhas do Programa Excel ${ }^{\circledR}$.

Os sistemas de produção foram diferenciados pela idade de abate e pelos índices tecnológicos que serviram para a estruturação dos modelos (estratégias de suplementação).

A construção das curvas de crescimento dos animais, a projeção da duração de cada ciclo e as posteriores análises de viabilidade econômica foram realizadas após a coleta dos dados e avaliação do desempenho produtivo biológico da literatura, sobretudo os consumos de suplemento e os ganhos de peso médios diários, referentes a seis experimentos utilizando ao todo 196 animais sob pastejo em pastagens tropicais alimentados com diferentes quantidades e formulações de suplementos múltiplos (Tabela 1) durante os períodos das águas e da seca, de acordo com quatro estratégias de suplementação, nas fases de recria e engorda.

As estratégias de suplementação avaliadas basearam-se na idade ao abate dos animais: abate aos 18 meses de idade: para a fase de recria neste sistema, assim como na terminação, foram utilizados os dados obtidos por Villela (2004), que utilizou 20 animais mestiços Holandês $\times$ Zebu e anelorados sob pastejo em piquetes uniformes de Brachiaria decumbens. Os animais receberam suplementação durante a seca pós-desmame, no período de 06 de agosto a 06 de novembro, quando apresentaram consumo médio de 1,18 $\mathrm{kg} /$ animal/dia de suplemento contendo em torno de 35,1\% de $\mathrm{PB}$, e durante a estação das águas subseqüente, no período de 26 de novembro de 2002 a 26 de fevereiro de 2003, quando apresentaram consumo médio de $0,5 \mathrm{~kg} /$ animal/dia (31,3\% PB); abate aos 24 meses de idade: este sistema é descrito em vários trabalhos na literatura (Detmann, 2004; Moraes, 2006; Acedo, 2004). Para a fase de recria neste sistema, foram utilizados os dados obtidos por Paulino et al. (1983), que utilizaram 56 animais azebuados com predominância de sangue Nelore. Os animais foram mantidos em pastagem tropical com predominância de capim-colonião (P. maximum) e receberam suplementação alimentar durante a seca pós-desmame, no período de 23 de junho a 10 de novembro, quando apresentaram consumo médio de $0,5 \mathrm{~kg} /$ animal/dia de suplemento contendo em torno de 33,3\% de PB. Durante a estação das águas, foram utilizados dados do 
Tabela 1 - Tipo, consumo diário de suplemento, teor de PB do suplemento e ganho médio diário de animais mantidos sob diferentes estratégias de suplementação

Table 1 - Supplement type, daily intake of supplement, content of CP of supplement, average daily gain for animals submitted to different supplement strategies

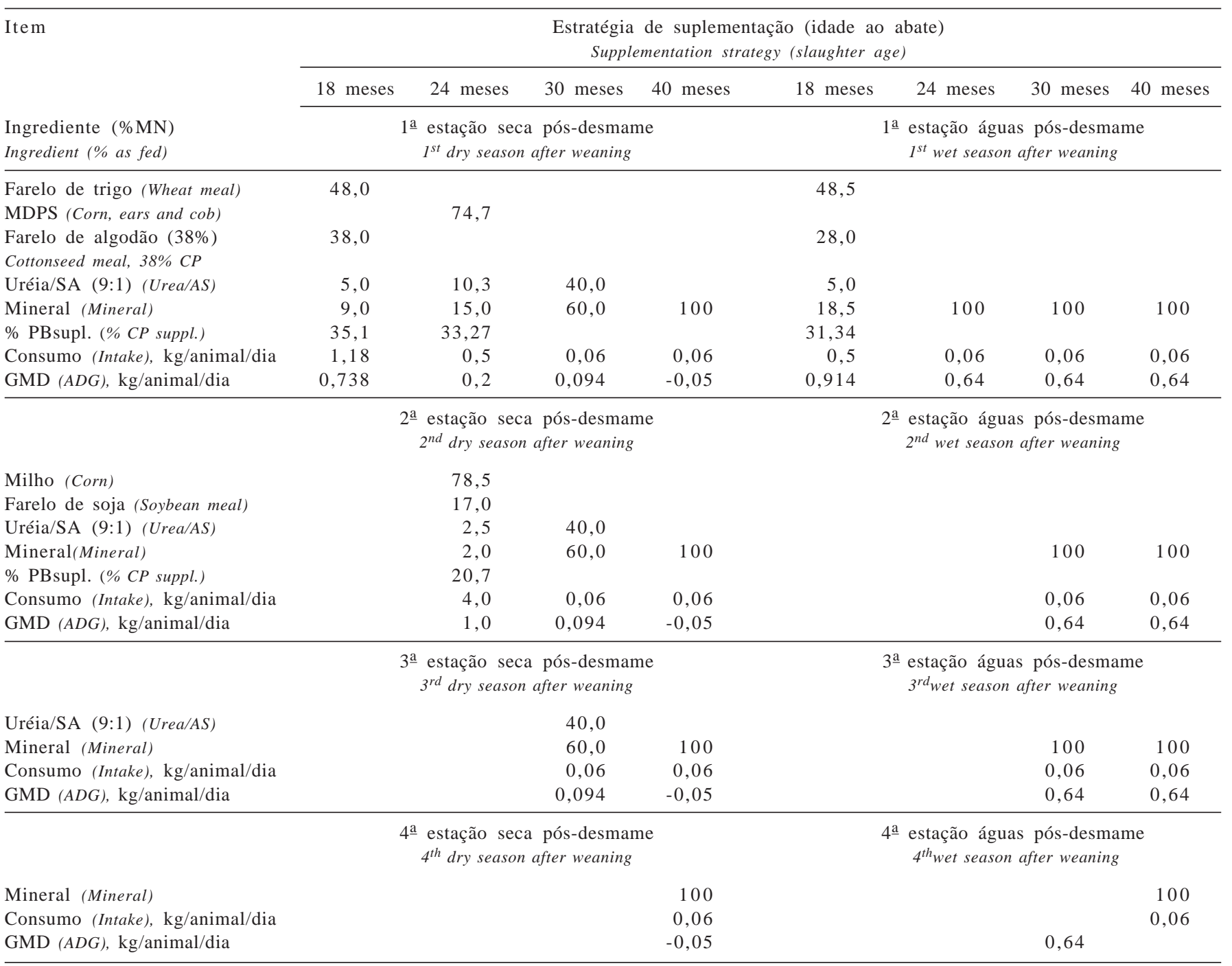

meses (months), dia (day)

trabalho de Villela (2004), que forneceu mistural como suplemento exclusivo a um grupo de 20 animais mestiços Holandês-Zebu e anelorados sob pastejo em piquetes uniformes de $B$. decumbens e observou consumo médio de $0,06 \mathrm{~kg} / \mathrm{animal} /$ dia. Para a fase de terminação, foram utilizados dados de Paulino et al. (2000). Nesse trabalho, 12 novilhos com peso médio de $361 \mathrm{~kg}$ foram distribuídos em três piquetes de $B$. decumbens e receberam suplementação múltipla durante a segunda seca pósdesmame antecedente ao abate, no período de 23 de junho a 25 de setembro, com consumo de 4,0 kg/animal/dia de suplemento contendo em torno de $20 \%$ de PB; abate aos 30 meses de idade - os animais foram abatidos aos 30 meses de idade. Para as fases de recria e terminação neste sistema, foram utilizados os dados de Paulino et al. (1982).
Nesse trabalho, os animais foram suplementados, tanto na primeira quanto na segunda seca pós-desmame, com sal nitrogenado, na quantidade de $0,06 \mathrm{~kg} / \mathrm{animal} / \mathrm{dia}(60,0 \mathrm{~g}$ de PB/animal/dia). Durante a estação das águas, foram utilizados dados do trabalho de Villela (2004), que suplementou com mistura mineral a dieta de um grupo de animais com consumo médio de $0,06 \mathrm{~kg} /$ animal/dia; abate aos 40 meses - os animais foram abatidos aos 40 meses de idade. Neste sistema, a dieta dos animais foi suplementada apenas com mistura mineral durante todo o período de recria e engorda. Nas análises foram utilizados dados do trabalho de Villela (2004), que forneceu mistura mineral como suplemento exclusivo a um grupo de animais e observou consumo médio de $0,06 \mathrm{~kg} / \mathrm{animal} / \mathrm{dia}$, como na maioria dos trabalhos conduzidos no período das águas, 
e uma perda de peso diária de $0,09 \mathrm{~kg}$ /dia durante os períodos de seca (Zanetti et al., 2000), caracterizando o efeito sanfona impresso pela sazonalidade da oferta de forragem. Em um contexto macro de sistema de produção, a estratégia 40 meses pode ser utilizada como referência ou testemunha, pois representa a média nacional de idade de abate de bovinos.

$\mathrm{O}$ indicadores de tamanho analisados foram: compra e venda anual de animais (cabeças); área total de pastagem (ha); número médio de animais no rebanho (cabeças); total do rebanho (animais) e total de unidades animais (UA); quantidade de arrobas (@) vendida no ano; mão-de-obra total (dias-homem/ano); fornecimento de concentrado para o rebanho (kg/ano); capital total investido ( $\mathrm{R} \$)$ : terra, animais, benfeitorias, máquinas e forrageiras não-anuais.

O número de animais comercializados por ano foi calculado multiplicando-se o número médio de animais no rebanho pelo número ciclos produtivos por ano.

Os indicadores zootécnicos analisados foram idade e peso inicial dos animais, idade e peso final dos animais, ganho de peso médio diário (kg/animal/dia), número de ciclos produtivos por ano, além de:

- taxa de lotação $(\mathrm{UA} / \mathrm{ha})=$ № total de unidade animais /área total (1);

- produtividade da terra $(\mathrm{kg} / \mathrm{ha} / \mathrm{ano})$ = produção anual de carne/área total (2);

- produtividade do concentrado (kg de peso vivo (PV) /kg de matéria natural $)$ = produção anual de carne/fornecimento anual de concentrado para o rebanho (3).

A partir desses parâmetros, foram determinados todos os custos, as receitas, as margens de lucro e a taxa de retorno do capital investido para cada modelo.

A medodologia de cálculo de custo se baseou nos métodos de custo operacional e de custo total (Vale \&
Gomes, 2001). Os coeficientes técnicos utilizados (Tabela 2) foram retirados do Anualpec (2004) e corrigidos pelo IGP-DI para dezembro de 2005. Os preços do boi gordo e de insumos foram referentes também a dezembro de 2005. O total de sal mineral fornecido foi calculado multiplicando-se a lotação média pelo consumo estimado de $0,060 \mathrm{~kg} /$ animal/dia e pelo período total de permanência dos animais na pastagem. As quantidades de suplemento foram calculadas utilizando-se a carga animal média multiplicada pelo consumo determinado e pelo período total de fornecimento da ração.

Os indicadores analisados foram calculados em $\mathrm{R} \$$ /ano e referem-se à renda bruta da atividade (RBA) pecuária equivalente à venda de animais; ao preço da arroba do boi gordo equivalente ao valor unitário da @ recebida, incluindo frete; ao custo operacional efetivo da atividade pecuária (COE), incluindo os gastos com mão-de-obra contratada, concentrados, manutenção de forrageiras não-anuais e suplementação mineral; sanidade; energia elétrica e combustíveis; impostos e taxas; reparos em benfeitorias, máquinas e equipamentos; compra de machos e outras despesas de custeio; e outros (Tabela 3).

Foram analisadas as diferenças na taxa de retorno do capital investido (DTRC) entre cada estratégia de suplementação em relação à estratégia de suplementação 4 , considerada tratamento testemunha, em virtude dos diferentes preços do quilo de suplemento. Os preços dos suplementos $(\mathrm{kg})$ foram expressos em equivalentes $\mathrm{kg}$ de PV de boi gordo, com base na matéria natural.

As estimativas dos coeficientes da regressão linear múltipla para DTRC de cada dieta das diferentes estratégias de suplementação foram obtidas utilizando-se sete diferentes custos para cada suplemento utilizado para o abate aos 18

Tabela 2 - Coeficientes técnicos utilizados na composição dos custos de produção dos modelos que caracterizaram os rebanhos das estratégias de suplementação, em preço nominal ( $R$ /UA), preços nominais ( $R$ \$/cab) e preços corrigidos ( $R$ /animal)

Table 2 - Technical coefficients used to compose the production costs of the models that characterize the herd of the supplementation strategies in nominal price $(R \$ / A U)$, nominal prices ( $R \$ /$ head) and corrected prices $(R \$ / h e a d)$.

\begin{tabular}{|c|c|c|c|}
\hline & $\begin{array}{c}\text { Nomimal }^{1} \\
\text { Nomimal }^{1}\end{array}$ & $\begin{array}{c}\text { Nomimal }^{2} \\
\text { Nomimal }\end{array}$ & $\begin{array}{c}\text { Corrigido }^{3} \\
\text { Corrected }\end{array}$ \\
\hline & $\mathrm{R} \$ / \mathrm{UA}$ & $\mathrm{R} \$ / \mathrm{cab}$ & $\mathrm{R} \$ / \mathrm{cab}$ \\
\hline Manutenção de pastagens (Pasture maintenance) & 8,51 & 11,78 & 12,49 \\
\hline Manutenção de benfeitorias (Facilities maintenance) & 15,54 & 21,52 & 22,81 \\
\hline Reparos de máquinas (Machine repairs) & 31,26 & 43,28 & 45,88 \\
\hline Administração (Administration) & 7,494 & 10,38 & 11,00 \\
\hline Outros (Others) & 2,652 & 3,67 & 3,89 \\
\hline
\end{tabular}

Fonte: ANUALPEC 2004 - RECRIA/ENGORDA SEMI-INTENSIVA - 2003

1 Unidade animal (U.A.) $=450 \mathrm{~kg}$ de peso vivo (Animal unit [A.U.] $=450 \mathrm{~kg}$ of body weight).

2 Boi gordo (fat bull) - @ $=\mathrm{R} \$ 50,00$, Bezerro (calf) - @ $=\mathrm{R} \$ 57,5(\mathrm{R} \$ 1,00=\mathrm{US} \$ 2,28)$

${ }^{3}$ Valores médios praticados no Brasil no ano de 2003, corrigidos para dez/2005 pelo IGP-DI (Average values used in Brazil in 2003 , corrected for December/2005 by IGP-DI. 
Tabela 3 - Indicadores econômicos analisados nas estratégias de suplementação Table 3 - Economical indicators analyzed in the supplementation strategies

$\begin{array}{cr}\text { Indicador econômico } & \text { Base de cálculo } \\ \text { Economical indicator } & \text { Economic mathematic }\end{array}$

Custo operacional total da atividade pecuária - COT (R\$/ano)

Total operational cost of the cattle business - COT (R\$/year)

Custo total da atividade pecuária - CT (R\$/ano)

Total cost of cattle business - CT (R\$year)

Margem bruta da atividade ${ }^{2}$ - MB (R\$/ano))

Gross margin of business - MB ( $R$ \$year

Margem líquida da atividade - ML (R\$/ano)

Net margin of business - ML (R\$/year)

Lucro da atividade (R\$ano)

Business profit (R\$/year)

Custo operacional efetivo por cabeça ao ano (R\$/cab/ano)

Effective operational cost per animal a year (R\$/animal/year)

Custo operacional efetivo por arroba vendida (R\$/ @ vendida)

Effective operational cost per arroba sold (RS/@ sold)

Custo operacional efetivo por hectare de pasto/terra ( $\mathrm{R} \$ / \mathrm{ha} / \mathrm{ano})$

Effective operacional cost for hectare of land ( $R \$ /$ ha/year)

Custo operacional total por cabeça ao ano (R\$/cab/ano)

Total operacional cost for animal a year (R\$/animal/year)

Custo total por arroba vendida (R\$/ vendida)

Total cost for @ sold (RS/@sold)

Custo total por área (R $\$ /$ ha/ano)

Total cost per area $(R \$ /$ ha/year)

Margem bruta por cabeça ao ano (R $\$ / c a b / a n o)$

Gross margin for animal a year (R\$/animal/year)

Margem bruta por arroba vendida (R\$/@ vendida)

Gross margin per arroba sold (RS/@ sold)

Margem bruta por área (R $\$ / h a / a n o)$

Gross margin per area $(R \$ /$ ha/year)

Margem líquida por cabeça ao ano (R\$/cab/ano)

Net margin for animal a year (R\$/animal/year)

Margem líquida por arroba vendida (R\$/@ vendida)

Net margin per arroba sold (RS/ @ sold)

Margem líquida por área ( $\mathrm{R} \$ / \mathrm{ha} / \mathrm{ano})$

Net margin per area $(R \$ /$ ha/year)

Lucro por cabeça ao ano (R\$/cab/ano)

Profit per animal a year (R\$/animal/year)

Lucro por arroba vendida (R\$/@ vendida)

Profit per arroba sold (RS/ @ sold)

Lucro por área (R\$/ha/ano)

Profit per area (R\$/ha/year)

Taxa de remuneração do capital investido com terra (\% ao ano)

Remuneration rate of the capital invested in land (\% a year)

COE + depreciação ${ }^{1}$ de máquinas, benfeitorias,

forrageiras não-anuais e animais de serviços

COE + depreciation of machines, improvements, tropical pastures and service animals

COT + remuneração do COE e do capital médio investido em animais, benfeitorias, máquinas, pastagens e terras COT + COE remuneration and of the average capital invested in animals, improvements, machines, no-annual pastures and lands RBA - COE

$\mathrm{RBA}-\mathrm{COT}$

RBA - CT

COE/produção anual de cabeças COE/animal production of animal COE/produção anual de arrobas COE/annual production of arrobas COE/área total do pasto

COE/total area of the pasture COT/produção anual de cabeças COT/animal production of animals CT/produção anual de arrobas CT/annual production of arrobas

CT/área total do pasto

CT/total area of the pasture

Preço do animal/cabeça ao abate - COE do animal

Animal price/animal at slaughter - Animal COE

Preço da arroba - COE da arroba

Price of arroba - arroba COE

Preço da produção ao ano - COE da produção/área total do pasto Production price a year - Production COE/total pasture area

Preço do animal - COT do animal

Price of animal - Animal COT

Preço da arroba - COT da arroba

Price of @ - @ COT

Preço da produção ao ano - COT da produção/área total do pasto Price of annual production - production COT / total area of the pasture

Preço animal/cabeça - CT animal

Price of animal - animal CT

Preço da arroba - CT arroba

Price of arroba - arroba $C T$

Preço da produção ao ano - CT da produção/área total do pasto Production price of year - production CT/total pasture area

ML/capital médio investido em animais, benfeitorias, máquinas, forrageiras não-anuais, terra e capital circulante (COE)

ML/average capital invested in animals, improvements, machines, no-annual pastures, earth and liquid capital (COE)

1 Para o cálculo da depreciação, foi utilizado o método linear (Hoffman et al., 1987)

2 Utilizou-se taxa de juros real de $4 \%$ ao ano sobre capital investido, referente à taxa média real (taxa nominal menos inflação) da caderneta de poupança.

1 For the calculation of the depreciation, a linear method was used (Hoffman et al., 1987).

2 Real interest rate was used of $4 \%$ a year on the invested capital, regarding to a real average rate (Nominal rates less inflation) of the savings account.

meses $(0,1 ; 0,2 ; 0,3 ; 0,4 ; 0,5 ; 0,6$ e 0,7 vezes o valor do quilo do boi gordo recebido pelo produtor), sete diferentes custos para cada kg de suplemento utilizado para o abate aos 24 meses $(0,1 ; 0,2 ; 0,3 ; 0,4 ; 0,5 ; 0,6$ e 0,7 vezes o valor do quilo do boi gordo recebido pelo produtor) e sete diferentes custos para cada kg de suplemento utilizado para o abate aos 30 meses $(0,2 ; 0,4 ; 0,6 ; 0,8 ; 1,0 ; 1,2$ e 1,4 vezes o valor do quilo do boi gordo recebido pelo produtor). No total, foram obtidas 105 combinações de resultados.

\section{Resultados e Discussão}

A estratégia de suplementação para o abate aos 40 meses imprime menor ganho médio diário (GMD) aos animais 
Tabela 4 - Indicadores zootécnicos e de tamanho utilizados na estruturação dos modelos que caracterizaram os rebanhos Table 4 - Zootechnic and range indicators used in the model structures that characterize the herd

Indicador zootécnico e de tamanho

Zootechnic and size indicator

Estratégia de suplementação (Abate) Supplementation strategy (Slaughter)

\begin{tabular}{rrrr}
18 meses & 24 meses & 30 meses & 40 meses \\
18 months & 24 months & 30 months & 40 months \\
\hline 8 & 8 & 8 & 8 \\
200 & 200 & 200 & 200 \\
450 & 450 & 450 & 450 \\
325 & 325 & 325 & 325 \\
0,72 & 0,72 & 0,72 & 0,72 \\
18 & 24 & 30 & 40 \\
10 & 16 & 22 & 32 \\
1.000 & 1.000 & 1.000 & 1.000 \\
1,0 & 1,0 & 1,0 & 1,0 \\
1.385 & 1.385 & 1.385 & 1.385 \\
& & & \\
0,76 & 0,48 & 0,35 & 0,23 \\
1,20 & 0,75 & 0,55 & 0,38 \\
1662 & 1038 & 755 & 519 \\
1662 & 1038 & 755 & 519 \\
384 & 240 & 175 & 118 \\
24.923 & 15.577 & 11.329 & 7.788 \\
\hline
\end{tabular}

Idade inicial (meses) (Initial age, months)

Peso médio inicial dos machos $(\mathrm{kg})$ (Average initial weight of the males)

Peso médio ao abate $(\mathrm{kg})$ (Average slaughter weight)

Peso médio (kg) $(2+3 / 2)$ (Average weight)

Peso médio (UA $1 / \mathrm{cab})(4 / 3)$

Idade ao abate (meses) (Slaughter age)

Ciclo de produção (meses) (6-1) (Production cycle, months)

Área de pastagem (ha) (Pasture area, ha)

Taxa de lotação (UA/ha) (Stocking rate)

Número de animais no rebanho ((8x9)/4) (Number of animals in the herd)

Resultados (Results)

Ganho médio diário ao ano $(\mathrm{kg} / \mathrm{dia})^{2}$ (Average daily gain a year, $\mathrm{kg} /$ day)

Número de ciclos por ano (12 meses/7) (Number of cycles a year, 12 months/7)

Compra anual de bezerros (10x12) (Annual purchase of calves)

Venda anual de cabeças (boi gordo) (13) (Annual market of heads, fat bull)

Produção de carne (kg/ha/ano) ((10x11)x(365/8)) (Beef production, kg/ha/year)

Quantidade de @ vendida no $\mathrm{ano}^{3}((14 \mathrm{x} 3) / 30)$ (Amount of arroba sold a year)

${ }^{1}$ Unidade Animal (U.A.) $=450 \mathrm{~kg}$ de peso vivo (Animal unit (A.U.) $=450 \mathrm{~kg}$ of body weight).

${ }^{2}$ Ganho médio diário no ano (kg/dia) (Average daily gain a year) $=\{[(3-2 / 7) \times 30,42] / 1000\}$.

3 Arroba de peso vivo (@) - 30 kg (@ of body weight - 30 kg).

e compromete severamente o ciclo de produção, em virtude da estacionalidade da produção das forrageiras tropicais, que provoca perda de peso durante a época seca e ganhos não suficientes para garantir o crescimento contínuo e ascendente da curva de crescimento durante o período das águas.

Geralmente, quando o crescimento do animal é retardado por subnutrição, há possibilidade de recuperação ao final da restrição alimentar e de crescimento a uma taxa mais acelerada (Euclides et al., 1998). Em vários trabalhos (Acedo, 2004; Figueiredo, 2005; Prohmann et al., 2004; Villela, 2004), animais mantidos sob estratégia de suplementação para abate aos 40 meses, ou seja, que passaram por restrição alimentar durante o período da seca, apresentaram ganhos de peso diários equivalentes ou inferiores, no período das águas subseqüente, aos de animais que mantiveram ou ganharam peso durante a seca com o fornecimento de nutrientes suplementares. Entretanto, os ganhos de peso mais proeminentes no período das águas, observados com animais sob pastejo recebendo apenas mistura mineral como suplemento (abate aos 40 meses), ocasionaram apenas uma compensação parcial e não foram suficientes para possibilitar pesos de abate às idades próximas às descritas em outros modelos (Figura 1). Essa tendência pode estar relacionada ao fato de que o animal criado exclusivamente em pastagem não satisfaz a demanda em nutrientes para manter um perfil ascendente da curva de crescimento. Esse fato foi claramente obser-

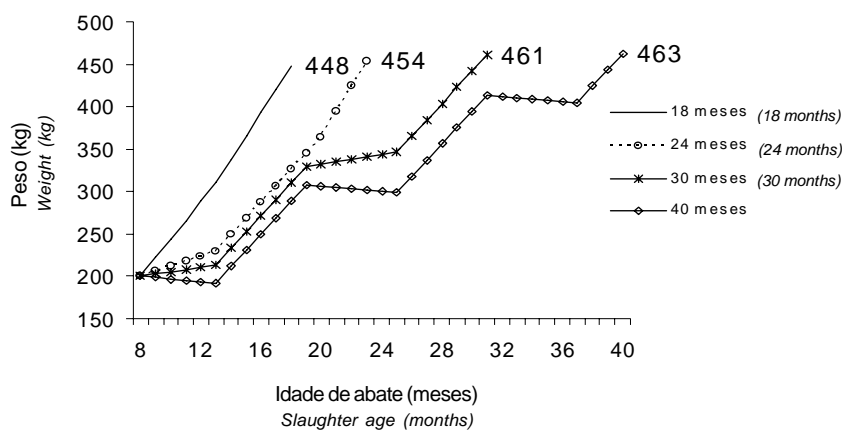

Figura 1 - Ganho de peso e idade ao abate de novilhos mantidos sob diferentes estratégias de suplementação.

Figure 1 - Weight gain and slaughter age of steers submitted to different supplementation strategies.

vado no desempenho produtivo dos animais abatidos aos 18 meses, nos quais foram observados os maiores ganhos de peso e, conseqüentemente, os maiores pesos de abate (450 kg), seguidos dos animais abatidos aos 24 , 30 e 40 meses de idade, respectivamente.

A bovinocultura desenvolvida à mercê dos fatores edafoclimáticos pode estender a idade ao abate (ou) à primeira cria para além dos 30 meses, ensejando taxas de desfrute de 15 a 17\% (Paulino et al., 2004). Desse modo, a maior precocidade dos sistemas de produção de carne bovina é alcançada somente se houver ajuste nutricional entre a oferta de forragem e a curva crescente de demanda do animal por nutrientes. A prática de suplementação visa também à maior produção por unidade de superfície (kg/ha/ 
ano), uma vez que aumenta a produção por animal incrementando a eficiência de utilização da forragem em seus picos de produção. Corroborando essa afirmativa, a estratégia de suplementação para abate aos 18 meses possibilitou ampliar a produção de carne ( $\mathrm{kg} / \mathrm{ha} / \mathrm{ano}$ ) em 37,5; 54,43 e, 69,27\% em relação às estratégias para abate aos 24 , 30 e 40 meses, respectivamente.

Existe uma relação direta entre a economicidade de sistemas com suplementação e o custo do suplemento. A escolha de um ou mais alimentos abundantes na região resulta em menor custo de aquisição e de transporte e possibilita ainda o acompanhamento dinâmico da relação preços de produtos/insumos (Pötter et al., 2000).

A suplementação teve grande participação na composição dos COE nas estratégias de suplementação para abate aos 18 e aos 24 meses. A participação do suplemento representou 20,92 e 24,77\% do valor total desta variável, correspondente a 128.456,82 e 115.138,72 kg de PV, respectivamente. Este resultado evidencia a intensificação do sistema produtivo na pecuária, pois está relacionado ao aumento da participação dos itens decorrentes da nutrição e genética nos custos de produção. A maior participação da suplementação no COE na estratégia de suplementação para abate aos 24 meses em relação ao abate aos 18 meses pode ser justificada pela quantidade expressiva de suplemento fornecida aos animais na fase de terminação (4 kg/ animal/dia), mesmo àqueles que não receberam suplementação na 2 2 época das águas pós-desmame, o que ocasiona maior ônus ao sistema.

A participação de componentes do COE, como sanidade, manutenção de pastagens, reparos de benfeitorias, máquinas e equipamentos, aumentou conforme diminuiu a intensificação do sistema de produção, característica de sistemas com baixo aporte de insumos.

Tabela 5 - Componentes do custo operacional efetivo (COE) utilizados na composição dos custos totais de produção dos modelos que caracterizam o rebanho das estratégias de suplementação, em percentual do COE (\% COE) e em quilos de peso vivo (kg PV)

Table 5 - Components of the effective operational cost (EOC) used to compose the total costs of production of the models that characterize the herd of the supplementation strategies in percentage of EOC (\% EOC) and in kilos of live weight ( $k g$ LW)

\begin{tabular}{|c|c|c|c|c|c|c|c|c|}
\hline \multirow[t]{3}{*}{$\begin{array}{l}\text { Componente } \\
\text { Compound }\end{array}$} & \multicolumn{8}{|c|}{$\begin{array}{l}\text { Idade ao abate } \\
\text { Slaughter age }\end{array}$} \\
\hline & \multicolumn{2}{|c|}{$\begin{array}{l}18 \text { meses } \\
18 \text { months }\end{array}$} & \multicolumn{2}{|c|}{$\begin{array}{l}24 \text { meses } \\
24 \text { months }\end{array}$} & \multicolumn{2}{|c|}{$\begin{array}{l}30 \text { meses } \\
30 \text { months }\end{array}$} & \multicolumn{2}{|c|}{$\begin{array}{l}40 \text { meses } \\
40 \text { months }\end{array}$} \\
\hline & $\begin{array}{l}\% \text { COE } \\
\% \text { EOC }\end{array}$ & $\begin{array}{l}\mathrm{kg} \mathrm{PV}^{*} \\
\mathrm{~kg} \mathrm{BW}\end{array}$ & $\begin{array}{l}\% \text { COE } \\
\% \text { EOC }\end{array}$ & $\begin{array}{l}\mathrm{kg} \mathrm{PV}^{*} \\
\mathrm{~kg} B W\end{array}$ & $\begin{array}{l}\% \mathrm{COE} \\
\% \text { EOC }\end{array}$ & $\begin{array}{c}\mathrm{kg} \mathrm{PV}^{*} \\
\mathrm{~kg} B W\end{array}$ & $\begin{array}{l}\% \mathrm{COE} \\
\% \text { EOC }\end{array}$ & $\begin{array}{c}\mathrm{kg} \mathrm{PV}^{*} \\
\mathrm{~kg} B W\end{array}$ \\
\hline $\begin{array}{l}\text { Mão-de-obra para manejo + encargos } \\
\text { Labor for management }+ \text { taxes }\end{array}$ & 2,24 & $13.774,85$ & 2,96 & $13.774,85$ & 3,16 & $9.183,23$ & 3,91 & $9.183,23$ \\
\hline $\begin{array}{l}\text { Administração } \\
\text { Administration }\end{array}$ & 1,49 & $9.120,14$ & 1,96 & $9.120,14$ & 3,13 & $9.120,14$ & 3,88 & $9.120,14$ \\
\hline $\begin{array}{l}\text { Assistência técnica } \\
\text { Technical attendance }\end{array}$ & 0,12 & 718,56 & 0,15 & 718,56 & 0,25 & 718,56 & 0,31 & 718,56 \\
\hline $\begin{array}{l}\text { Sal mineral } \\
\text { Mineral salt }\end{array}$ & 0,00 & 0,00 & 1,52 & $7.051,59$ & 3,06 & $8.913,70$ & 6,95 & $16.341,78$ \\
\hline $\begin{array}{l}\text { Sal mineral - uréia } \\
\text { Mineral salt - urea }\end{array}$ & 0,00 & 0,00 & 0,00 & 0,00 & 3,16 & $9.202,68$ & 0,00 & 0,00 \\
\hline $\begin{array}{l}\text { Suplemento múltiplo } \\
\text { Multiply supplement }\end{array}$ & 20,92 & $128.456,82$ & 4,25 & $19.763,18$ & 0,00 & 0,00 & 0,00 & 0,00 \\
\hline $\begin{array}{l}\text { Concentrado terminação } \\
\text { Finishing concentrate }\end{array}$ & 0,00 & 0,00 & 20,52 & $95.375,54$ & 0,00 & 0,00 & 0,00 & 0,00 \\
\hline $\begin{array}{l}\text { Sanidade } \\
\text { Health }\end{array}$ & 1,03 & $6.316,19$ & 1,36 & $6.316,19$ & 2,17 & $6.316,19$ & 2,69 & $6.316,19$ \\
\hline $\begin{array}{l}\text { Manutenção de pastagens } \\
\text { Pasture maintenance }\end{array}$ & 1,69 & $10.356,61$ & 2,23 & $10.356,61$ & 3,56 & $10.356,61$ & 4,41 & $10.356,61$ \\
\hline $\begin{array}{l}\text { Reparos de benfeitorias } \\
\text { Facilities repairs }\end{array}$ & 3,08 & $18.912,07$ & 4,07 & $18.912,07$ & 6,50 & $18.912,07$ & 8,04 & $18.912,07$ \\
\hline $\begin{array}{l}\text { Reparos de máquinas e equipamentos } \\
\text { Machines and equipments repairs }\end{array}$ & 6,20 & $38.043,20$ & 8,19 & $38.043,20$ & 13,07 & $38.043,20$ & 16,18 & $38.043,20$ \\
\hline $\begin{array}{l}\text { Energia elétrica e combustíveis } \\
\text { Electric energy and fuels }\end{array}$ & 0,60 & $3.687,49$ & 0,79 & $3.687,49$ & 1,27 & $3.687,49$ & 1,57 & $3.687,49$ \\
\hline $\begin{array}{l}\text { Outros } \\
\text { Others }\end{array}$ & 0,53 & $3.227,47$ & 0,69 & $3.227,47$ & 1,11 & $3.227,47$ & 1,37 & $3.227,47$ \\
\hline $\begin{array}{l}\text { Compra de machos ( } 1 \text { ano) - ágio de } 15 \% \\
\text { Males purchase }\end{array}$ & 62,12 & $381.391,06$ & 51,29 & $238.369,42$ & 59,57 & $173.359,57$ & 50,70 & $119.184,71$ \\
\hline $\begin{array}{l}\text { Total COE } \\
\text { Total EOC }\end{array}$ & 100,00 & $614.004,46$ & 100,00 & $464.716,31$ & 100,00 & $291.040,91$ & 100,00 & $235.091,45$ \\
\hline
\end{tabular}

* $\mathrm{kg}$ boi gordo $-\mathrm{R} \$ 1,67$ (referente a dezembro de 2005) (kg of fat bull $-R \$ 1.67$ [December, 2005]). 
Tabela 6 - Simulação de renda bruta (RB), custo operacional efetivo (COE), custo operacional total (COT), custo total (CT), margem bruta $(\mathrm{MB})$, margem líquida (ML), lucro, total por ano, por total de animais, por arroba vendida e por área e taxa de retorno do capital investido (TRC) nas diferentes estratégias de suplementação

Table 6 - Simulation of gross income (GI), effective operational cost (EOC), total operational cost (TOC), total cost (TC), gross margin (GM), net margin (LM), profit, total peryear, per total of animals, per arroba sold and per area, return rate of the invested capital (RIC), in the different supplementation strategies

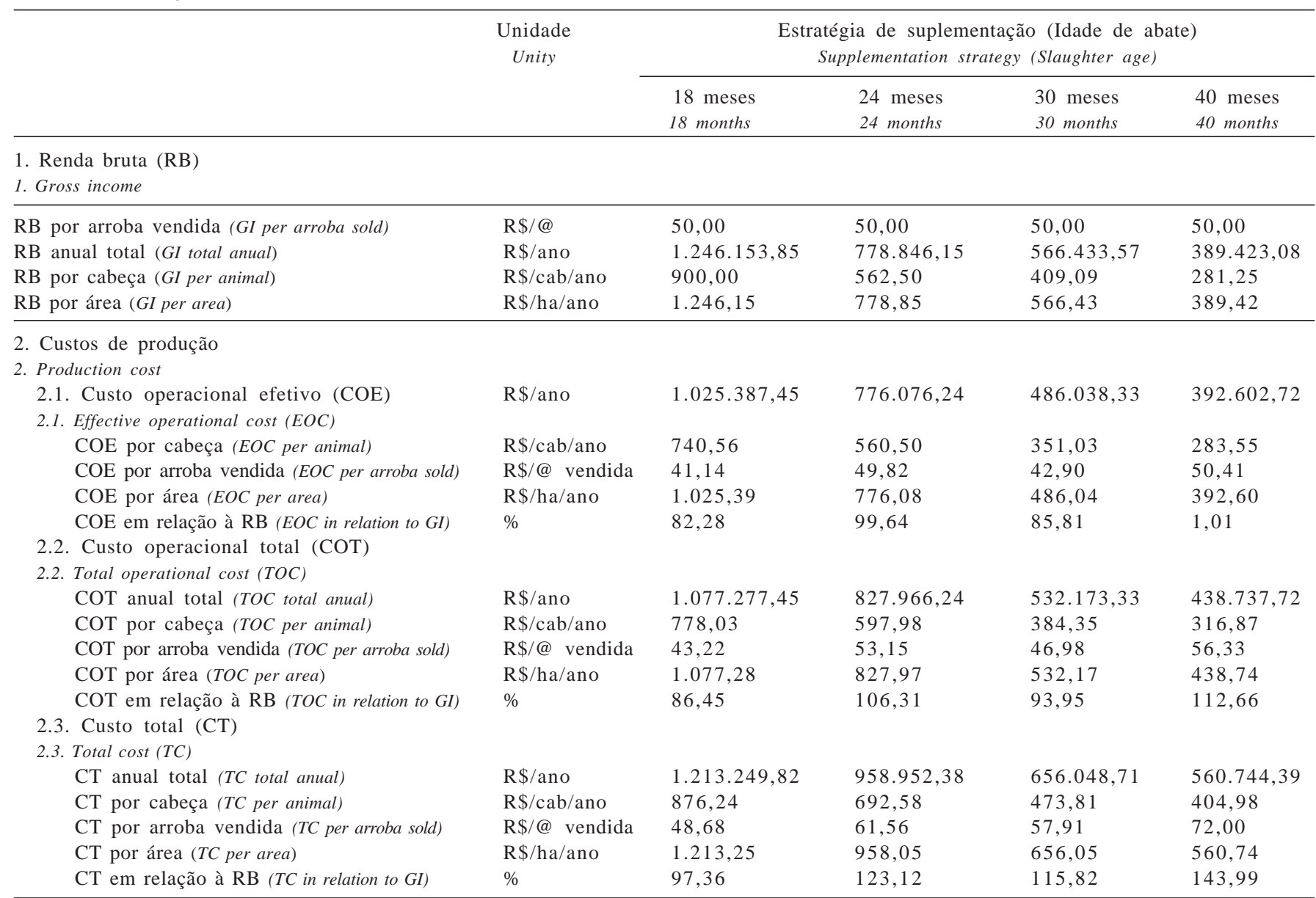

Taxa real anual de juros de poupança*

$4 \%$ ao ano

Real annual rates of savings account

3. Margem bruta

3. Gross margin

Anual (Annual)

Por cabeça/ano (Per animal/year)

Por arroba vendida (Per arroba sold)

Por área (Per area)

$220.766,39 \quad 2.769,82$

$\mathrm{R} \$$ /cab/ano $\quad 159,44$

R\$/@vendida 8,86

R\$/ha/ano

220,77

$\begin{array}{ll}\text { 168.876,39 } & -49.120,08 \\ \mathrm{R} \$ / \text { cab/ano } & 121,97 \\ \mathrm{R} \$ \text { / @endida } & 6,78 \\ \mathrm{R} \text { /ha/ano } & 168,88\end{array}$

$34.260,24$
$-35,48$
$-3,15$
$-49,12$

$-49.314,64$

24,74

3,02

$-3.179,64$

58,06

7,10

$-2,30$

0,18

2,77

80,40

$-0,41$

$-3,18$

4. Margem líquida

4. Net margin

Por cabeça/ano (Per animal/year)

Por arroba vendida (Per arroba sold)

Por área (Per area)

5. Lucro

5. Profit

Anual (Annual)

Por cabeça/ano (Per animal/year)

Por arroba vendida (Per arroba sold)

Por área (Per area)

6. Taxa de retorno do capital onvestido c/

terra (TRC) \% no período

6. Rates of return of the invested capital with land

* Média 1995 a 2003 (Average values 1995 to 2003). 
Nas simulações, a margem bruta (MB) é o resultado da diferença entre a receita bruta e os desembolsos (COE). $\mathrm{Na}$ margem líquida (ML), além dos desembolsos, é subtraída a depreciação e, para chegar ao lucro (L), subtrai-se o custo de oportunidade do capital envolvido na atividade, calculado pela taxa de $4 \%$ ao ano. Esses três indicadores são apresentados também em porcentagem da receita bruta (Tabela 6), ou seja, indica o que sobrou após cobrir o custo operacional efetivo (MB\%), o custo operacional total (ML\%) e o custo total (L\%).

A MB foi positiva ( $\mathrm{RB}>\mathrm{COE}$ ) para as estratégias de suplementação para abate aos 18, 24 e 30 meses e indica que esses sistemas remuneram os gastos de custeio e sobreviverão pelo menos a curto prazo. O mesmo não ocorreu na estratégia de suplementação para abate aos 40 meses, que apresentou MB negativa, indicando insustentabilidade a curto prazo. Mantendo essa situação, a melhor solução para sistemas que operam com esta estratégia seria a interrupção da produção, pois eliminaria os custos variáveis (COE) e reduziria o déficit na MB.

A ML para os sistemas de abate aos 18 e 30 meses foi positiva e comprova estabilidade e possibilidade de expansão do empreendimento, enquanto a estratégia para abate aos 24 e 40 meses apresentou ML negativa. Para o abate aos 24 meses, no entanto, existem condições de suportar os custos operacionais efetivos ( $\mathrm{MB}>0$ ), desse modo, o produtor pode continuar produzindo por determinado período, embora com problema de descapitalização a médio prazo.

O pior desempenho econômico verificado na estratégia de suplementação para abate aos 24 meses em relação ao abate aos 18 e aos 30 meses pode ser explicado pelos fatores que alteram a eficiência alimentar dos bovinos e pela lei dos rendimentos marginais decrescentes em sistemas biológicos (Mitscherlich, 1904, citado por Raij, 1991; Russel 1984; Bargo et al. 2003; Euclides, 2005; Góes, 2005) e descrita pela teoria microeconômica (Varian, 2003).

O fornecimento de suplemento na fase de terminação na estratégia para abate aos 24 meses tornou o sistema menos eficiente biológica e economicamente em comparação às estratégias com suplementação ao longo das fases de crescimento animal. Os aumentos na eficiência alimentar decresceram com a maturidade, caracterizando resposta não-linear, explicada pelo crescente direcionamento do alimento (ou energia) para o tecido adiposo. Embora a deposição de proteína seja menos energeticamente eficiente (mcal/mcal) que a deposição de gordura, quando avaliado o peso de tecido depositado (kg músculo/mcal ingerida), esta deposição foi superior, pois, para cada unidade de ganho de proteína, aproximadamente três unidades de água (e apenas uma de gordura) foram depositadas em associação (Lanna, 1997).
Os rendimentos marginais (acréscimo de produto/ acréscimo de fator de produção) apresentaram tendência decrescente curvilínea ou linear à quantidade do fator de produção. A quantidade ótima de fator de produção a ser empregado é aquela em que sua respectiva taxa de rendimento marginal se igual à razão preço do fator de produção/preço do produto (Px/Py). Quantidade acima ou abaixo deste ponto indica irracionalidade no uso do recurso produtivo (Hoffman et al., 1987). Portanto, o maior nível de suplementação para o abate aos 24 meses em relação ao abate aos 18 e 30 meses foi outro fator que comprometeu o desempenho econômico, possivelmente por exigir uma quantidade de suplemento cujo rendimento marginal foi superior à razão $\mathrm{Px} / \mathrm{Py}$.

Em sistemas biológicos, Monod (1949), citado por Russell (1984), observou que a taxa de crescimento microbiano depende da concentração de substrato e ambos foram relacionados à cinética de saturação típica de sistemas enzimáticos. Russel (1984) confirmou que as bactérias comportam como enzimas por apresentarem resposta curvilínea na taxa de crescimento ao aumento do fornecimento do substrato.

Bargo et al. (2003), em extenso trabalho de revisão sobre suplementação em vacas de leite a pasto, observaram que a taxa marginal de aumento na produção de leite apresentou comportamento curvilíneo e reduziu em alguns estudos quando os níveis de concentrado foram superiores a 3,3 e $4,4 \mathrm{~kg} / \mathrm{animal} /$ dia.

Euclides (2005), avaliando um banco de dados obtido de 23 trabalhos, observaram comportamento semelhante no ganho de peso diário de bovinos em decorrência da oferta média de concentrado no período seco do ano.

O resultado negativo para as margens bruta e líquida na estratégia de suplementação para abate aos 40 meses é reflexo do baixo número de animais no sistema e da baixa produção de peso vivo, conseqüência do baixo ganho de peso diário. Produtores que detêm rebanhos com esta baixa produtividade sobrevivem na marginalidade do sistema. Com poucas condições de oferecerem produtos (carne) e preços competitivos, esses pecuaristas quase sempre perdem terras e mercado para agricultores mais eficientes e com culturas mais rentáveis. Pilau et al. (2003), avaliando sistemas de produção para novilhas de corte, observaram que os animais exclusivamente em pastejo sob disponibilidade de forragem baixa apresentam ganho de peso vivo suficiente apenas para cobrir os custos operacionais efetivos.

O lucro positivo apresentado exclusivamente pela estratégia de suplementação para abate aos 18 meses significa que a alocação de recursos nesse sistema pro- 
porciona melhor retorno em relação ao investimento alternativo no caso de aplicação na caderneta de poupança. Desse modo, a estratégia de suplementação para abate aos 18 meses é a única que permite sustentabilidade a longo prazo. A análise da taxa de retorno do capital investido reforça os argumentos sobre a superioridade da estratégia para abate aos 18 meses por ser a única a apresentar taxa superior $(32,43 \%)$ à fornecida pela caderneta de poupança.

A adoção de um nível mais racional de suplementação, distribuído ao longo das fases de recria e terminação, associada à maior diluição das exigências de mantença proporcionada pela maior taxa de crescimento (Blaser, 1990), justifica o melhor desempenho obtido com esta estratégia.

Ressalta-se, porém, que a rentabilidade do sistema produtivo é local dependente, ou seja, as análises feitas neste estudo não representam a totalidade das diversas condições em que os sistemas produtivos são impostos. Por isso, a avaliação sob diferentes condições de preço dos insumos e produtos deve ser preterida. Assim, as equações de regressão da estimativa da diferença na taxa de retorno do capital investido em relação à estratégia para abate aos 40 meses (DTRC), para abate aos 18 meses, 24 meses e 30 meses, em função de diferentes combinações de preços dos suplementos (Tabela 7) permitem essa avaliação.
Valores de DTRC (\% ao ano) superiores a zero indicam que substituição da estratégia para abate aos 40 meses pelas estratégias para abate aos 18, 24 e 30 meses, respectivamente, aumenta a taxa de retorno do capital investido, ou seja, aumenta a rentabilidade do sistema de produção de carne, enquanto valores abaixo de zero reduzem a taxa de retorno do capital investido. Dessa forma, o ponto de equilíbrio é aquele em que o custo dos insumos empregados na formulação do suplemento utilizado no plano nutricional do rebanho é igual ao ganho adicional de desempenho (kg de peso vivo) proporcionado pelo plano. Neste sentido, a determinação das DTRC (\% ao ano) define a melhor estratégia de suplementação sob diferentes preços relativos de suplementos em qualquer época e/ou região.

A DTRC foi positiva para a estratégia de suplementação para abate aos 18 meses (91,8\%), aos 24 meses (24,5\%) e aos 30 meses (100\%). O preço de equilíbrio do suplemento na estratégia para abate aos 30 meses foi 3,91 kg de boi gordo/kg, superior aos preços analisados. Embora a estratégia para abate aos 30 meses tenha apresentado menor sensibilidade às variações nos preços, o resultado desta estratégia gerou apenas $20,29 \%$ da MLda de renda anual proporcionada na estratégia de suplementação para abate aos 18 meses.

Tabela 7 - Equações da diferença da taxa de retorno do capital (DTRC) entre as estratégias de suplementação para abate aos 18 e 40 meses (equação 1), aos 24 e 40 meses (equação 2) e aos 30 e 40 meses (equação 3)

Table 7 - Equations of difference of capital return rate (DCRR) among the supplementation strategies for slaughter at 18 and at 40 mo(equation 1), 24 and 40 months (equation 2) and at 30 and 40 months (equation 3)

$\begin{aligned} & \text { ETRC } \\ & \text { CDRR }\end{aligned}$
Equaçãon

\section{Conclusões}

A suplementação estratégica a bovinos em pastagens tropicais é uma alternativa economicamente viável para recria e terminação de machos de corte. Entre as estratégias de suplementação avaliadas, o abate aos 18 meses foi a melhor, seguidos pelas estratégias de abate aos 30, 24 e aos 40 meses. $\mathrm{O}$ alto consumo de suplemento e sua concentração em uma fase de pior conversão alimentar são as causas do desempenho econômico menos satisfatório da estratégia para abate aos 24 meses em relação ao abate aos 30 meses. Estratégias com baixo uso de tecnologias, vigentes na estratégia de abate aos 40 meses, são economicamente insustentáveis a curto prazo por não compensarem os custos operacionais efetivos. No entanto, a decisão sobre a melhor estratégia depende de combinações favoráveis de preços relativos dos suplementos; por isso, a melhor estratégia de suplementação deve ser definida pela diferença na taxa de retorno do capital investido em relação à ausência de suplementação.

\section{Literatura Citada}

ACEDO, T.S. Suplementos múltiplos para bovinos em terminação, durante a época seca, e em recria, nos períodos de transição seca-águas e águas. Viçosa, MG: Universidade Federal de Viçosa, 2004. 58p. Dissertação (Mestrado em Zootecnia) - Universidade Federal de Viçosa, 2004.

ANUALPEC. Anuário estatístico da pecuária brasileira. FNP Consultoria e Agroinformativos. São Paulo: 2004. 376p. 
BLASER, R.E. Manejo do complexo pastagem - animal para avaliação de plantas e desenvolvimento de sistemas de produção de forrageiras. In: REUNIÃO ANUAL SOCIEDADE BRASILEIRA DE ZOOTECNIA, 28., 1990, Piracicaba. Anais... Piracicaba: Sociedade Brasileira de Zootecnia, 1990. p.157-205.

BARGO, F.; MULLER, L.D.; KOLVER, E.S. et al. Invited review: production and digestion of supplemented dairy cows on pasture. Journal of Dairy Science, v.86, n.1, p.1-42, 2003.

DETMANN, E.; PAULINO, M.F.; ZERVOUDAKIS, J.T. et al. Níveis de proteína bruta em suplementos múltiplos para terminação de novilhos mestiços em pastejo durante a época seca: desempenho produtivo e características de carcaça. Revista Brasileira de Zootecnia, v.33, p.169-180, 2004.

EUCLIDES, V.P.B.; MEDEIROS, S.R. Suplementação animal em pastagens e seu impacto na utilização das pastagens. In: SIMPÓSIO SOBRE MANEJO DA PASTAGEM, 22., 2005, Piracicaba. Anais... Piracicaba: Fundação de Estuos Agrários Luiz de Queiroz, 2005. p.33-70.

EUCLIDES, V.P.B.; EUCLIDES FILHO, K.; ARRUDA, Z.J. et al. Desempenho de novilhos em pastagens de Brachiaria decumbens submetidos a diferentes regimes alimentares. Revista Brasileira de Zootecnia, v.27, n.2, p.246-254, 1998.

FGVDADOS - Informações econômicas on-line. Disponível em: <http://www.fgvdados.com.br> Acesso em: 1/12/2005.

FIGUEIREDO, D.M. Fontes de proteína em suplementos múltiplos para novilhas de corte em pastejo durante os períodos das águas e transição águas-seca. Viçosa, MG: Universidade Federal de Viçosa, 2005. Dissertação (Mestrado em Zootecnia) - Universidade Federal de Viçosa, 2005.

GOES, R.H.T.B.; MÂNCIO, A.B.; LANA, R.P. et al. Recria de novilhos mestiços em pastagens de Brachiaria brizantha, com diferentes níveis de suplementação, na região Amazônica. Desempenho animal. Revista Brasileira de Zootecnia, v.34, n.5, p.1740-1750, 2005.

HOFFMANN, R.; SERRANO, O.; NEVES, E.M. et al. Administração da empresa agrícola. 5.ed. São Paulo: Pioneira, 1987. 325p.

LANNA, D.P.D. Fatores condicionantes e predisponentes da puberdade e da idade de abate. In: SIMPÓSIO SOBRE PECUÁRIA DE CORTE: PRODUÇÃO DO NOVILHO DE CORTE, 4., 1997, Piracicaba. Anais... Piracicaba: Fundação de Estuos Agrários Luiz de Queiroz, 1997. p.41-78.

MATTOS, W.R.S. Limites da eficiência alimentar em bovinos leiteiros. In: REUNIÃO ANUAL DA SOCIEDADE BRASILEIRA DE ZOOTECNIA, 41., 2004, Campo Grande. Anais... Campo Grande: SBZ: Embrapa Gado de Corte, 2004. p.239-247.

MORAES, E.H.B.K; FONSECA, M.P.; ZERVOUDAKIS, J.T. et al. Níveis de proteína em suplementos múltiplos para novilhos mestiços em pastejo durante o período de transição seca/águas. Revista Brasileira de Zootecnia, v.35, n.5, p.2135-2143, 2006.

NOGUEIRA, M.P. Viabilidade na adoção de tecnologia. In: Gestão Competitiva para a Pecuária, 2003, Jaboticabal. Anais... Jaboticabal: UNESP, 2003. p.4-32.

PAULINO, M.F.; FIGUEIREDO, D.M.; MORAES, E.H.B.K. et al. Suplementação de Bovinos em pastagens: uma visão sistêmica. In: SIMPÓSIO DE PRODUÇÃO DE GADO DE CORTE, 4., 2004, Viçosa, MG. Anais... Viçosa, MG: Universidade Federal de Viçosa, 2004. p.93-144.
PAULINO, M.F.; DETMANN, E.; VALADARES FILHO, S.C. Soja grão e caroço de algodão em suplementos múltiplos para terminação de bovinos mestiços em pastejo. REUNIÃO ANUAL DA SOCIEDADE BRASILEIRA DE ZOOTECNIA, 38, 2000. Anais... Viçosa/MG, 2000 (CD-ROM).

PAULINO, M.F.; SILVA, H.M.; RUAS, J.R.M. et al. Efeitos de diferentes níveis de uréia sobre o desenvolvimento de novilhas zebus. Arquivo Brasileiro de Medicina Veterinária e Zootecnia, v.35, n.2, p.231-245. 1983.

PAULINO, M.F.; REHFELD, O.A.M.; RUAS, J.R.M. et al. Alguns aspectos da suplementação de bovinos de corte em regime de pastagem durante a época seca. Informe Agropecuário, v. 89, n.8, p.28-31, 1982.

PILAU, A.; ROCHA, M.G.; SANTOS, D.T. Análise econômica de sistemas de produção para recria de bezerras de corte. Revista Brasileira de Zootecnia, v.32, n.4, p.966-976, 2003.

POTTER, L.; LOBATO, J.F.; NETTO, C.G.M. Análises econômicas de modelos de produção com novilhas de corte primíparas aos dois, três e quatro anos de idade. Revista Brasileira de Zootecnia, v.29, n.3, p.861-870, 2000.

PROHMANN, P.E.F.; BRANCO, A.F.; JOBIM, C.C. et al. Suplementação de bovinos em pastagem de Coastcross (Cynodon dactylon (L.) Pers) no verão. Revista Brasileira de Zootecnia, v.33, n.3, p.792-800, 2004.

RAIJ, B.V. Fertilidade do solo e adubação. São Paulo, Piracicaba: Ceres, Potafos, 1991. 343p.

RIESCO, A.; SERÉ, C. Análisis económicas de resultados de las pruebas de pastoreo. In: LASCANO, C.; PIZARRO, E. (Eds). Evaluación de pasturas con animales. Alternativas metodológicas. Cali: CIAT, 1996. p.201-232.

ROCHA, M.G.; RESTLE, J.; SANTOS, D.T. et al. Produção animal em sistemas intensivos de utilização de pastagem de aveia mais azevém. In: REUNIÃO DA SOCIEDADE BRASILEIRA DE ZOOTECnIA, 38., 2001, Piracicaba. Anais...Piracicaba: Sociedade Brasileira de Zootecnia, 2001. p.191.

RUSSEL, J.B. Factors influencing competition and composition of the ruminal bacterial flora. In: GILCHRIST, F.M.C.; MACKIE, R.I. (Eds.) The herbivore nutrition in the subtropics and tropics. Craighall: Science Press, 1984. p.313-345.

VALE, S.M.L.R.; GOMES, M.F.M. Análise econômica da empresa rural. Brasília, ABEAS. (Curso de Especialização por Tutoria à Distância. Curso de Administração Rural - Módulo 2). 2001. 101p.

VARIAN, H.R. Microeconomia. Princípios básicos. Rio de Janeiro: Elsevier, 2003. 778p.

VILlelA, S.D.J. Fontes de proteína em suplementos múltiplos para bovinos em pastejo. Viçosa, MG: Universidade Federal de Viçosa, 2004. 116p. Tese (Doutorado em Zootecnia) - Universidade Federal de Viçosa, 2004.

ZANETTI, M.A.; RESENDE, J.M.L.; SCHALCH, F. et al. Desempenho de novilhos consumindo suplemento mineral proteinado convencional ou com uréia. Revista Brasileira de Zootecnia, v.29, n.3, p.935-939, 2000. 